\title{
Methods to Estimate the Risk of Sudden Cardiac Death: A Review Article
}

\author{
Mahmoud Abdelnaby ${ }^{1 *}$, Abdallah Almaghraby ${ }^{2}$ and Ashraf ElAmin ${ }^{2}$ \\ ${ }^{1}$ Department of Clinical and Experimental Internal Medicine, University of Alexandria, Egypt \\ ${ }^{2}$ Department of Cardiology, University of Alexandria, Egypt
}

Submission: November 13, 2017; Published: November 22, 2017

*Corresponding author: Mahmoud Abdelnaby, Cardiology and Angiology Unit, Department of Clinical and Experimental Internal Medicine,

Medical Research Institute, University of Alexandria, Egypt, Tel: +201007573530; Email: Mahmoud.hassan.abdelnabi@outlook.com

\begin{abstract}
Sudden cardiac death (SCD) remains a major health issue for several reasons: from its prevalence (20\% of total mortality in the industrialized world) to the devastating psycho-social impact on the families of the patients. Also, due to poor understanding of etiologies and how to manage properly, it represents a challenge for cardiologists [1]. This review article aimed to summarize the methods currently used as risk stratifies for SCD.

Keywords: Sudden cardiac death; Risk stratifies; Ventricular fibrillation; Left ventricular ejection fraction; Signal-averaged ECG; Heart rate variability
\end{abstract}

\section{Introduction}

Sudden cardiac death (SCD) is defined as the natural death from cardiac causes heralded by abrupt loss of consciousness within 1 hour of the onset of an acute change in cardiovascular status. Preexisting heart disease may or may not be present [2]. Almost $50 \%$ of all deaths caused by coronary heart disease to sudden and unexpected and occur shortly within 1 hour after the onset of symptoms, [3] the usual mechanism is acute ischemia and ventricular fibrillation or by reentrant ventricular tachycardia on top of chronic scar formation [4].

Methods to Estimate the Risk of Sudden Cardiac Death

Multiple non-invasive approaches have been developed to detect the presence of arrhythmogenic factors that initiate and maintain VT or VF in patients with ischemic and non-ischemic heart disease. The specific techniques are those that detect

a) Slowed conduction (QRS duration, signal-averaged electrocardiogram [SAECG]).

b) Heterogeneities in ventricular re-polarization (QT interval, QT dispersion, T-wave alternans).

c) Imbalance in autonomic tone (heart rate variability [HRV], heart rate turbulence). d) Extent of myocardial damage and scar formation (left ventricular ejection fraction [LVEF], 6-minute walk).

e) Ventricular ectopy (long term ambulatory monitoring) [5].

\section{Left ventricular ejection fraction}

There are abundant data supporting the use of LVEF to risk-stratify patients with ischemic and non-ischemic cardiomyopathies. Although low LVEF identifies a group with relatively increased risk, the majority of SCDs occur in patients with more preserved LVEF, which highlights the limited sensitivity of this technique [5].

\section{QRS duration}

QRS duration is a simple measure of the duration of ventricular activation measured on the 12-lead electrocardiogram (ECG) and is a manifestation of intraventricular or interventricular conduction delay or block. A moderate amount of data show that increased QRS duration identifies patients at higher risk for SCD, although the data are not uniform [5].

\section{QT interval and QT dispersion}

The QT interval is a reflection of the summed ventricular action potential durations. QT dispersion (the maximal difference 
between QT intervals in the surface ECG) was postulated to reflect dispersion of myocardial recovery and associated with arrhythmia risk [5].

\section{Signal-averaged ECG}

Late potentials refer to low-amplitude signals that occur after the end of the QRS complex. Signal averaging to reduce noise allows high gain amplification and filtering to expose these signals on the surface ECG. Abundant data show that an abnormal SAECG may identify patients with prior MI at risk for SCD. Given the high negative predictive value of this test, it may be useful for the identification of patients at low risk [5].

\section{Ventricular ectopy and NSVT}

There is abundant information linking the detection of ventricular arrhythmias (VPBs, NSVT) on ambulatory ECG in post-MI patients with left ventricular dysfunction for risk assessment for sudden death [5].

\section{Heart rate turbulence}

Heart rate turbulence describes the short-term fluctuation in sinus cycle length that follows a VPB [6]. Emerging data show that abnormal heart rate turbulence is associated with increased mortality [5].

\section{Exercise capacity and NYHA class}

Although overall mortality increases as the severity of heart failure increases, the proportion of deaths due to sudden cardiac arrest from a treatable ventricular tachyarrhythmia decreases as more patients die of progressive pump failure [5].

\section{T-wave alternans}

T-wave alternans is a reflection of repolarization alternans at the level of the single cell and most likely arises when heart rate exceeds the capacity of cardiac cells to cycle intracellular calcium [7]. A moderate amount of data suggests that T-wave alternans may be useful for risk stratification for SCD [5].

\section{Programmed electrical stimulation}

Despite a large, albeit somewhat conflicting database on the role of electrophysiologic testing for risk profiling, particularly in patients with advanced heart disease, its use is currently more limited than in the past [5].

\section{Baroreceptor sensitivity}

A moderate amount of data suggests that Baroreceptor Sensitivity (BRS) may be useful for risk stratification for SCD in patients with coronary artery disease. Further studies are needed to establish the clinical utility, if any, of this parameter for risk stratification [5].

\section{Short-term HRV}

Analysis of HRV provides a mean of assessing autonomic nervous system modulation of the sinus node to infer autonomic activity on the rest of the heart; particularly the ventricles. Cardiac arrhythmias are often initiated by or occur in patients with enhanced sympathetic and diminished parasympathetic tone. Thus, it has been proposed that an analysis of HRV, particularly its parasympathetic effects on the sinus node, can potentially predict mortality [5]. Several studies showed that low short-term HRV is associated with increased risk of cardiovascular death.

\section{Long-term HRV}

Abundant data showed that depressed HRV is a strong predictor of all-cause mortality [5]. Recent studies showed that HRV is a better marker of total mortality. Further researches are needed to establish the validity of long-term HRV in the risk stratification of SCD $[4,8]$ (Figure 1).

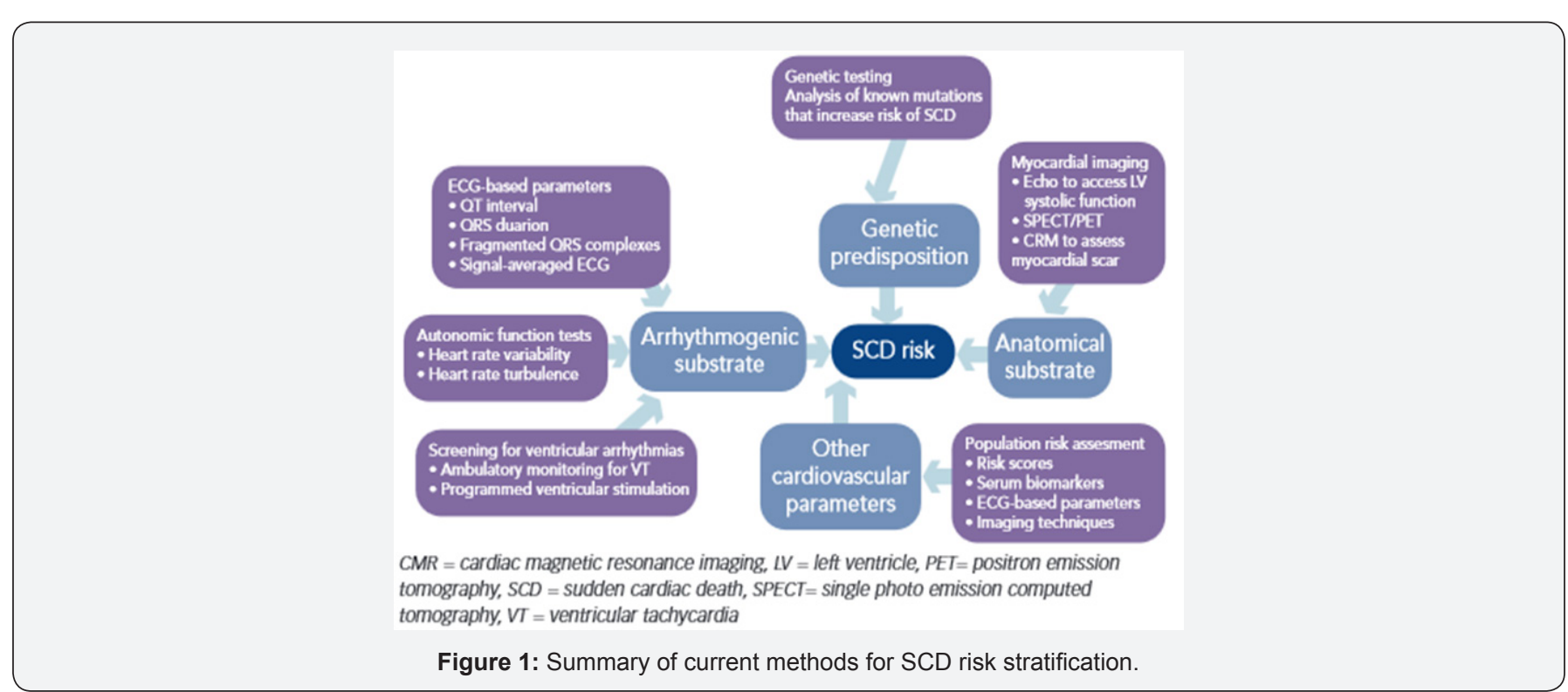




\section{Conclusion}

Sudden cardiac death remains a major health problem with further research is required for more advanced methods to define people at risk for sudden cardiac death.

\section{References}

1. Wellens HJ, Schwartz PJ, Lindemans FW, Buxton AE, Goldberger JJ, et al. (2014) Risk stratification for sudden cardiac death: current status and challenges for the future. Eur Heart J 35(25): 1642-1651.

2. Myerburg RJ, Castellanos A (2015) Cardiac Arrest and Sudden Cardiac Death. In: Mann DL, Zipes DP, Libby P, Bonow RO, Braunwald E (Eds.) Braunwald's Heart Disease: A Textbook of Cardiovascular Medicine. $\left(10^{\text {th }}\right.$ edn), Elsevier Saunders, USA, pp. 821-860.

3. Nichol G, Thomas E, Callaway CW, Hedges J, Powell J, et al. (2008) Regional variation in out-of-hospital cardiac arrest incidence and outcome. JAMA 300(12): 1423-1431.

4. Israel CW (2014) Mechanisms of sudden cardiac death. Indian Heart J 66 (Suppl 1): S10-S17.
5. Goldberger JJ, Cain M, Hohnloser SH, Kadish AH, Knight BP, et al (2008) American Heart Association/American College of Cardiology Foundation/Heart Rhythm Society scientific statement on noninvasive risk stratification techniques for identifying patients at risk for sudden cardiac death: a scientific statement from the American Heart Association Council on Clinical Cardiology Committee on Electrocardiography and Arrhythmias and Council on Epidemiology and Prevention. Circulation 118(14): 1497-1518.

6. Watanabe MA, Joseph EM, Robert S, Mark EJ (2002) Effects of ventricular premature stimulus coupling interval on blood pressure and heart rate turbulence. Circulation 106(3): 325-330.

7. Valgimigli M, Serruys P, Tsuchida K, Vaina S, Morel M, et al. (2007) Cyphering the complexity of coronary artery disease using the syntax score to predict clinical outcome in patients with three-vessel lumen obstruction undergoing percutaneous coronary intervention. Am Cardiol 99(8): 1072-1081.

8. Priori SG, Aliot E, Blomstrom LC, Bossaert L, Breithardt G, et al. (2003) Update of the guidelines on sudden cardiac death of the european society of cardiology. Eur Heart J 24(1): 13-15.

Your next submission with Juniper Publishers will reach you the below assets

- Quality Editorial service

- Swift Peer Review

- Reprints availability

- E-prints Service

- Manuscript Podcast for convenient understanding

- Global attainment for your research

- Manuscript accessibility in different formats

( Pdf, E-pub, Full Text, Audio)

- Unceasing customer service

Track the below URL for one-step submission https://juniperpublishers.com/online-submission.php 